\title{
Analysis and Prioritization of Effective Strategies for Agile Supply Chain Case Study: Pharmaceutical Industry in Iran
}

\author{
Houshang Taghizadeh*1 \\ AmirReza Valyani 2 \\ Ardeshir Bazrkar ${ }^{3}$ \\ 1Department of Management, Tabriz Branch, Islamic Azad University, Tabriz, Iran \\ ${ }^{2-3}$ Department of Industrial Management, Tabriz Branch, Islamic Azad University, Tabriz, Iran \\ 2-3Department of Industrial Management, East Azerbaijan Science and Research Branch, Islamic Azad University \\ Tabriz, Iran ; *Corresponding Author: E-mail: Taghizadeh@iaut.ac.ir
}

\section{Doi:10.5901/mjss.2015.v6n6s2p376}

\section{Abstract}

Organizations are forced to move to maintain and improve its position among competitors, given the competitive environment prevailing in the current environment and the rapid pace of change.The mobility and competitiveness cannot be implemented unless all parts of the supply chain, including suppliers, manufacturers and distributors act together with high level of integration and agility. Competitiveness is one of the most important factors considered in the development of the pharmaceutical industry in light of the growing competitiveness in the industry. The study was an attempt to study the implications and factors affecting supply chain agility to determine important criteria and then propose strategies for supply chain agility for the industry. Finally ranked them using the fuzzy TOPSIS method in Multi Attribute Decision Making (MADM).

Keywords: agile supply chain, agility strategies, pharmaceutical industry, fuzzy TOPSIS, Multi Attribute Decision Making (MADM).

\section{Introduction}

Organizations are today faced with quick response to customers' demands, difficult competitive conditions in the market and increased the level of environmental development (Power D. et al., 2001). Agility is the paradigm that leads to the ability of the organization to understand the market (changes in customer needs and tracking new demands), achieving a competitive strategic plan to acquire skills, providing structural changes and a process for meet the needs, increasing the information transparency within the organization, producing less costly products with the highest quality, optimizing the use of resources, economies of scale and enhancing the organization in providing new and differentiated products and services with added value for the customers. This paradigm enables organization to deal effectively with continuous and unpredictable changes in their environment to in addition to the reactive response to the changing environment, meet customers and workers needs in a predictive way and benefit from opportunities in turbulent and uncertain environment. The agility concept was first published in a report by Yakoka entitled (strategies for manufacturing firms in the twenty-first century: industrial specialists view), following the meeting of many experts and industry executives to find the causes of the failure of companies to deal with challenges and environmental changes. Competitiveness is one of the most important factors considered in the development of industry and the pharmaceutical industry is no exception. The importance of competition in this sector is such that the state tries to balance it with the economic growth rate (Alshawi, 2003).

To achieve agility is the establishment of an integrated supply chain in an environment where there is a similar concept is applied (Rachel Mason-Jones, 2000). Also, improved agility in the supply chain is among the most important factors that will win the competition. Agile supply chain is highly developed in recent years as a response to the dynamic and volatile market. An agile supply chain needs high level of flexibility for re-shaping to meet the business environment requirements. Therefore, an agile supply chain can be a dynamic network of member firms considered with their structure exposed to constant changes in the environment (Wu C., 2010). Companies, to gain competitive advantage in the variable business environment and the efficiency of operations, must be in line with suppliers and customers in addition to its institutions and cooperate for an acceptable level of agility (Christopher, 2002). Pharmaceutical companies to guarantee their survival and development must enhance supply chain agility based on understanding and responding to fleeting market opportunities and high technology, given the changes in the country's market with increased drug 
production, large investments in research and development and high rates of change in the industry and increased competition.

This article aimed to identify key effective strategies on supply chain agility in the pharmaceutical industry, and rank them using Multi Attribute Decision Making (MADM) techniques in order to focus on the management of these strategies

\section{Theoretical Backgrounds and Literature Review}

Agile supply chain is to achieve dynamic integration and agile manufacturing in the competitive and dynamic market environment with better flexibility and rapid response capability, communicate with suppliers, producers, manufacturers, distributors and end users in the process of supply and demand. Agility supply chain requires a comprehensive management to provide a material, product processing, distribution, sales, customer service and etc. Therefore, it is believed that agility is the attribute needed for organizations future competitive pressures and competitive advantage (Giachetti et al., 2003).

Several studies have been done on agile supply chain agility including, Christopher (2000), Tolon, (2000), Svensson, (2001), Baker, (2008) and Agarwal et al., (2007). One aspect of agility is chosen and developed in most of these studies. For example, Bal et al., 1999 have focused on virtual teams to create agility. Svensson emphasized on trust within supply chain networks for agile supply chain. Finally, Matthias Holweg (2005) emphasized on sensitivity and responsiveness to the market trend and Patrick Swafford et al., (2008) stressed on the importance of flexibility to create an agile supply chain.

Lue used seven organizational agility factors in the evaluation of institution agility: customer's enrichment, accountability, dynamic structure, teamwork and collaboration, organizing to create competitive advantage, accommodating people and information, and product information content. Mohamed Zein et al, based on the above factors provided a four-factor framework with a view to evaluating the agility of the organization Gldman model. The framework factors include: customers enrichment, organize to create competitive advantage, alignment of people and information, and accountability.

Yusef et al., (1999), provided a total 32 agility factors and brought them together in four key competency management, virtual enterprise, regeneration capability, knowledge-based enterprises axis. It seems that these enablers in fact are agility aspects and determine the general behavior of firms. Sharif and Zhank presented a conceptual model for agility in their article. This model includes three major parts. The first part is on the agility that forces the firm to seek a new position for flow and continuity of its business and gain a competitive advantage. These factors make the firm to review and reconstitute strategy. The second part is about agility capabilities that include to reaction to environmental changes, competence, flexibility and speed. The third part of this model is agility supplier's that includes methods and functions, as well as the structure, technology, personnel and innovation. These methods are easy to implement and focusing on key issues. However, agile supply chain is based on integration of organization customer sensitivity, processes, networks and information systems.

Power \& Sohal in his article addressed the critical success factors and maintain an agile supply chain as: participatory leadership style, computer-based technology, resource management, continuous improvement enablers, relationship with suppliers, on time production methods, and or technologies utility. They surveyed 1,000 companies and found that considering and applying the aforementioned factors helps to create and maintain agile supply chain.

Yusef et al., know the agile supply chain measures as the following:

Cooperation with competitors, long-term partnerships with customers and suppliers, leverage the effectiveness of human resources by networking with other companies, difficult conditions that makes cooperation with other company's inevitable, alliance with business counterparts, integration of information with other companies on computer systems, giving higher priority to the alliance to market penetration (Yusef et al., 2004).

According to Adel Azar et.al., with respect to work and achieve success factors in the supply chain, as a result of research done in the literature of supply chain agility, 11 more common factors were identified in the following table (Azar et al., 1389):

Table 1: Success key factors in the of agile supply chain on Adel Azar

\begin{tabular}{|c|c|c|c|c|c|}
\hline Success Factors & Appropriate planning & Sensitivity and response to market & Processes integration & The use of IT & Flexibility \\
\hline Customer satisfaction & Product quality & The development of staff skills & Reduce costs & $\begin{array}{c}\text { Delivery } \\
\text { speed }\end{array}$ & $\begin{array}{c}\text { New Product } \\
\text { Introduction }\end{array}$ \\
\hline
\end{tabular}


Jafarnejad \& Darwish identified accountability, competence, flexibility and speed as indicators related to supply chain agility, while definitions and sub-criteria were made (Jafarnejad, 2009).

Zand Hesami et al., in their research concluded that addressing supply chain agility leads to the organization agility. On the other hand, supply chain agility cannot be felt in practice since superior supply chain strategy which is organizational strategy is considered as a mover of (stimulus) the supply chain and as long as an organization is not going to develop agile strategy, Also, according to study a number of 25 variables were identified to be effective on supply chain, shown in the table below (Zand Hesami et al., 2009).

Table 2: Key factors in the success of agile supply chain services in view of Zand Hesami et al

\begin{tabular}{|l|l|l|l|l|l|}
\hline Sensitivity to Market & Virtual Integration & Delivery speed & $\begin{array}{l}\text { The accuracy of } \\
\text { the information }\end{array}$ & $\begin{array}{l}\text { New Product } \\
\text { Introduction }\end{array}$ & $\begin{array}{l}\text { Central and } \\
\text { cooperative planning }\end{array}$ \\
\hline Processes integration & $\begin{array}{l}\text { The use of information } \\
\text { technology tools }\end{array}$ & $\begin{array}{l}\text { Reduce supply time } \\
\text { (Lead Time) }\end{array}$ & $\begin{array}{l}\text { Improve service } \\
\text { levels }\end{array}$ & $\begin{array}{l}\text { Minimize and } \\
\text { reduce costs }\end{array}$ & $\begin{array}{l}\text { Customer } \\
\text { satisfaction }\end{array}$ \\
\hline Improve the quality of & Minimize uncertainty & $\begin{array}{l}\text { Develop a spirit of } \\
\text { trust (increasing the } \\
\text { level of trust) }\end{array}$ & $\begin{array}{l}\text { Minimize } \\
\text { resistance to } \\
\text { change }\end{array}$ & $\begin{array}{l}\text { Reduce new } \\
\text { product } \\
\text { development time }\end{array}$ & $\begin{array}{l}\text { Increased levels of } \\
\text { customization }\end{array}$ \\
\hline $\begin{array}{l}\text { Increase the number of new } \\
\text { products }\end{array}$ & $\begin{array}{l}\text { Alignment with global } \\
\text { distribution }\end{array}$ & $\begin{array}{l}\text { Improve the level of } \\
\text { customer service }\end{array}$ & $\begin{array}{l}\text { Improve the } \\
\text { reliability of } \\
\text { delivery }\end{array}$ & $\begin{array}{l}\text { Better meet the } \\
\text { needs of the } \\
\text { market }\end{array}$ & Reduce setup time \\
\hline Improve production capacity & & & & & \\
\hline
\end{tabular}

Based on the literature review, the authors developed a conceptual model of agile supply chain in Figure 1 that has reached its peak in many research studies (Christopher, 2004). According to this model, agility drive is change and transformation. Although not new, but few changes occur faster than before. Confusion and uncertainty in the business environment has been a major cause of failure of the supply chain. Different companies have different characteristics and undertake different conditions and specific changes that may be unique to them. However, there are common characteristics that can have the same results for all companies. Therefore supply chain agility required level can be determined by the organization based on the evaluation of the work environment. Agile supply chain addresses transformation, uncertainty and lack of predictability in the business environment and provides appropriate response to the changes, to do so, an agile supply chain needs a distinct and varied capabilities. These capabilities can be divided into four main elements:

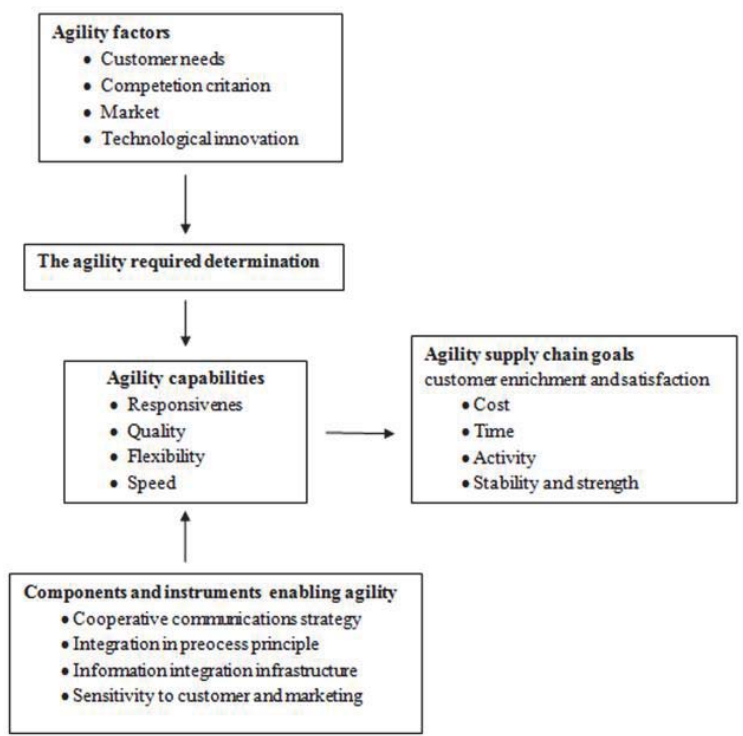

Figure 1: Conceptual model of agile supply chain 
Pharmaceutical companies need to enhance the agility based on understanding and responsiveness to fleeting market opportunities and technology to ensure the survival and progress given the changes in the pharmaceutical market and becoming more competitive, with increased drug production as well as high investment in research and development and high rates of change in the industry.

\section{Methodology}

The process of this study after study and review of earlier relevant research literature include the following steps:

\subsection{The experts team formation.}

3-2- Explain the mechanisms affecting the agility of the supply chain in the pharmaceutical industry

3-3- The rankings of determined strategies using fuzzy TOPSIS Multi Attribute Decision Making (MADM)

3-1- The expert's team formation: the selected experts in this study include a number of top managers of industry experts who are at least with 15 years of management experience.

3-2- Explain the mechanisms affecting the agility of the supply chain in the pharmaceutical industry: we provide effective strategies to the pharmaceutical industry supply chain agility according to the study of theoretical factors affecting supply chain agility, literature and other study results.

3-2-1- Outsourcing: Outsourcing is the transfer of some of the internal workings of an organization to the external supplier based on the contract. In fact, in outsourcing production agents (staff, facilities, equipment, technology and other assets) and decision-making authority (responsibility and the right to make decisions on activities) are often entrusted in addition to the transfer of activities (Greaver, 1999). Outsourcing improve the performance of companies and organizations by downsizing and making the organization agile, reducing and controlling costs, access to non-local resources, sharing risk and difficult tasks management, or even impossible (Khodaverdi et al., 2010).

3-2-2- Network and information system integration in the supply chain: One of the differences between agile systems with other systems is the high information content. In addition, the amount of information exchanged between partner companies is high and any organization key information explicitly needs to be protected. The Agile organizations require advanced information and flexible communication systems that ensure the secure data flow with the adaptability to changing conditions (Fathi et al., 2006).

3-2-3- Culture variability, empowerment and human resource training programs: the management and motivation of human resources is one of the issues to move towards an agile organization. The most difficult part in realizing the objective of agile management is not organizational and structural change, but a change in the culture and management practices (Fathian et al., 2006).

3-2-4- Use flexible and agile organizational structures: Organizational structure is one of the major factors affecting the agility. Forming a suitable structure can lead to business benefits from agility through a focus on staff and innovation and creativity caused by their effective cooperation and thus enable organizations to attain features such as flexibility and high-speed in the face of environmental change and accountability and responsively to predictable and unpredictable changes (Raschke, 2010).

3-2-5- The establishment and use of technology and flexible manufacturing systems: agile manufacturing is a new concept to improve the competitiveness of businesses, so that customers need not only to be met faster than ever, but also the manufacturers to have flexible production systems need to easily cope with design changes and reconfiguration compatible equipment. In order to adapt to changes in the composition and deployment of the orders, these systems and technology are essential (Ghasemi et al., 2010).

3-2-6-The establishment of appropriate supply chain performance evaluation systems: Performance evaluation activities helped maintain aspects of an organization's strategic and market objectives and operational aspects of the organization and should provide the key data for vital aspects of knowledge management, planning, control and monitoring of progress. These activities should change in response to changes in the market environment and operations with close relationship to provide grounds for active and leading management (Shepherd, 2006).

3-2-7-Create strong relationships based on trust in the supply chain: in the modern world, trust and greater reliance on suppliers and covenant partners is inevitable, therefore, require a new style of relations. There can be no limit in a developed firm and trust and commitment slogan must be to dominate (Shahaee).

3-2-8-Establish a Customer Relationship Management system (CRM): customer agility is corporate agility in applying customer voice to obtain market intelligence and explore competitive opportunities. In the customer agility literature, customer agility is defined as the degree to which the company is able to sense and respond to customer- 
oriented opportunities for innovation and competitive activity (Khodami et al., 2012). Establishing customer relationship systems and coordination between them and the rest of the supply chain can lead to seize the opportunities of the market and surpass its competitors.

3-2-9- Focusing on Research and Development (R \& D): the rapid growth of technology, risk taking and ongoing and increased unforeseen changes in the world market has made the new product development teams to face with increasing pressure to reduce production cycle of the product along with reducing the cost of developing, maintaining appropriate and correct innovation with respect to the philosophy of earlier, better and cheaper produce (Griffin, 2001) to determine the factors affecting the agility of the new product development process. Therefore, the role of $R$ \& $D$ chain agility is very significant

3-2-10-Privatization: the private sector Engaging and consequent increasing competition in the pharmaceutical industry makes it dynamics and various companies in a competitive market environment produce the medicine, so it cannot be monopolized by anyone. It is no doubt that the participation of the private sector in the supply chain and further reduces of dependency on government play a role in the pharmaceutical industry supply chain agility.

\subsection{The rankings of determined strategies using fuzzy TOPSIS Multi Attribute Decision Making (MADM):}

3-3-1- Multiple Attribute Decision Making: MADM is a mathematical model and refers to a problem solving approach that is used to choose on option from a limited number of options (Rao, 2008). MADM methods are known for ease of use; combined procedures (if properly combined) can maintain the strength and create multiple sources of knowledge and experience (Shih, 2007).

3-3-2- Fuzzy Logic: Fuzzy Logic was presented by professor Lotfi Zadeh in 1965 as a mathematical theory to model the ambiguity and uncertainty of human perception and ideas (Lin et al., 2007).

Fuzzy approach is an excellent tool to deal and cope with the uncertainties and variables of uncertainty and modeling language variables. Fuzzy computing (fuzzy logic) attempts to cast a foundation to argue about approximate reasoning (model inaccurate propositions) using fuzzy sets (Menhaj, 2007). Generally, uncertainties can be classified in three main categories: implicit or approximate data, linguistic terms and rather the interval data (Cheng, 2000). The data model Uncertainties is of the third type where data is not specified values but a range of data values. Different types of triangular and trapezoidal fuzzy numbers are more common because of the ease of use in modeling and interpretation (Petroni et al, 2002). In this paper, the triangular fuzzy numbers are used. as follows.

A triangular fuzzy number , ñ, in Figure 3-1 is shown with a triplet as $(\mathrm{l}, \mathrm{m}, \mathrm{u})$ that its membership function is defined

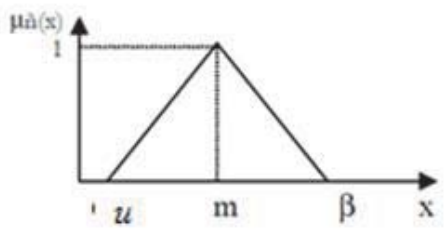

Figure 2: The triangular fuzzy numbers

Where, $[l, u]$ is range of support and points $(m, 1)$ are heads. Triangular number are with a membership function that includes both linear $L$ (left) and R (right) and connected to each other at the head (m, 1), which makes graphic representations and operations with triangular numbers very easy. It is important that they are made simply on the basis of very little information.

Two triangle numbers M1 and M2 drawn in the diagram 3-2 have to be considered.

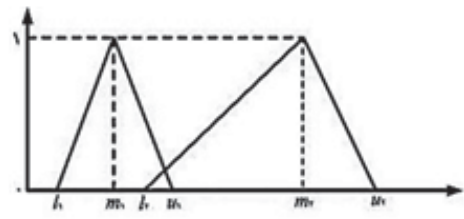

Figure 3: Fuzzy numbers $\mathrm{m}^{1}, \mathrm{~m}^{2}$ 


\subsection{TOPSIS method}

TOPSIS method (Technique Ordered Preference by Similarity to the Ideal Solution) is the definition of positive ideal solution and negative ideal solution (Wang, 2008) and is based on the fact that the selected option is in the shortest distance to the idea solution. Positive and negative ideal solution is an imaginary solution in which all the parameter values are the same order of maximum and minimum values in the database (Rao, 2008). In summary, the positive ideal solution combines the best values available in the criteria and negative ideal solution is the worst value of the available criteria (Wang, 2008).

In short, fuzzy TOPSIS algorithm can be expressed as follows:

Step one: Forming a decision making team and then determine the options and their evaluation criteria.

Step two: Determine the full option rates according to each criterion using preset speech variables.

Step three: Normalization of normalized fuzzy decision matrix.

Step four: Forming weight normalization phase matrix.

Step five: Determine the fuzzy positive ideal solution and negative ideal solution.

Step six: Calculate the options Euclidean distance: The Euclidean distance of each of the options is calculated separately.

Step seven: Calculate the relative closeness to the ideal solution.

Step eight: Ranking the options according to nearby factor index calculated in the previous step

\section{Determine Supply Chain Agility Criteria in the Pharmaceutical Industry}

As stated in the previous discussions and consultations with experts, five parameters including responding to changes speed, increasing the quality, responsiveness to market, reduced costs and innovation were selected as the main determinants of the agile supply chain.

Then a questionnaire was designed to rank strategies that influence on agility supply chain in pharmaceutical industry using fuzzy TOPSIS technique and completed by a team of experts and the following range was used for the quantification of the comments.

Table 3: Triangular numbers range

\begin{tabular}{|c|c|c|c|c|}
\hline \multicolumn{3}{|c|}{ The triangular fuzzy } & \multirow{2}{*}{ Linguistic terms } & Impact \\
\cline { 1 - 2 } Upper limit & Intermediate & 3 & Very high & 5 \\
\hline 4 & 3 & 2 & High & 4 \\
\hline 4 & 3 & 1 & Moderate & 3 \\
\hline 3 & 2 & 0 & Low & 2 \\
\hline 2 & 1 & 0 & Very low & 1 \\
\hline 1 & 0 & &
\end{tabular}

After data collection through questionnaires and calculations in Excel, the results were obtained in the form below.

Table 4: Data analysis criteria

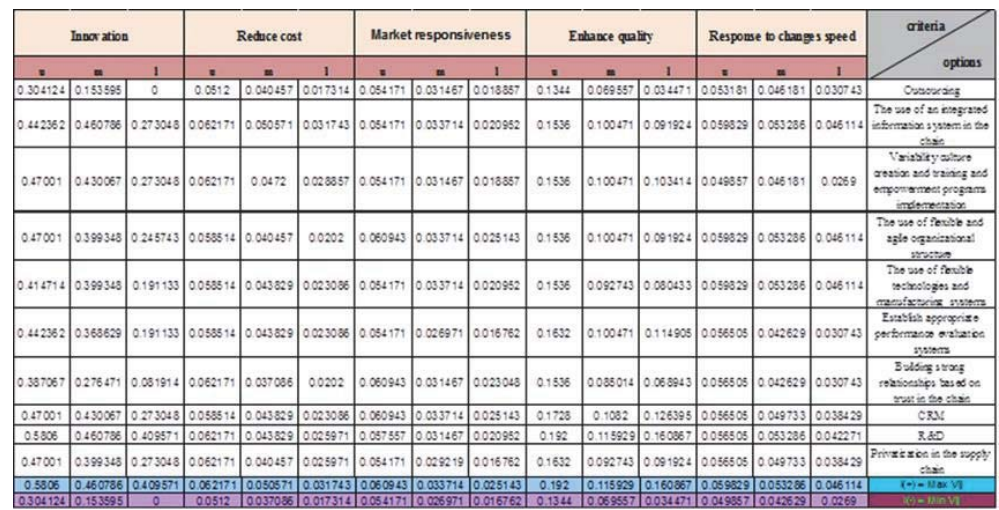


Table 5: Distance from the ideal and Rating

\begin{tabular}{|c|c|c|c|l|}
\hline Rank & $\mathbf{d}^{+}$ & $\mathbf{d}^{-}$ & CC & Options \\
\hline 10 & 0.17 & 0.00 & 0.03 & Outsourcing \\
\hline 1 & 0.20 & 0.13 & 0.41 & The use of an integrated information system in the chain \\
\hline 4 & 0.29 & 0.10 & 0.26 & Variability culture creation and training and empowerment programs implementation \\
\hline 7 & 0.27 & 0.08 & 0.23 & The use of flexible and agile organizational structure \\
\hline 5 & 0.28 & 0.09 & 0.25 & The use of flexible technologies and manufacturing systems \\
\hline 8 & 0.26 & 0.07 & 0.21 & Establish appropriate performance evaluation systems \\
\hline 9 & 0.20 & 0.03 & 0.12 & Building strong relationships based on trust in the chain \\
\hline 3 & 0.30 & 0.11 & 0.26 & CRM \\
\hline 2 & 0.34 & 0.13 & 0.28 & R\&D \\
\hline 6 & 0.26 & 0.07 & 0.23 & Privatization in the supply chain \\
\hline
\end{tabular}

\section{Conclusion}

Agile supply chain is the key to a successful organization with the increased competition among supply chains operating units of various industries. No doubt the swift action of any organization depends on the agility of the rest of the chain. Pharmaceutical industry is no exception with the competitiveness is growing day by day. In this case, given the characteristics of the industry to examine ways of influencing the supply chain agility seems necessary. Studies show that several factors are involved in the supply chain agility, as a result effective strategies can be explained. Studies show that the reaction to changes rate, increased quality, responsiveness to market, reduced costs, and innovation can be as basic criteria considered in the pharmaceutical industry supply chain agility. Thus, the explained strategies for supply chain agility in the pharmaceutical industry of the country were ranked based on expert opinion. For this purpose and in order to increase the accuracy fuzzy TOPSIS Multi Attribute Decision Making (MADM) techniques were used. The results of calculations indicate that the use of integrated information systems in the supply chain, focusing on research and development $(R \& D)$ and the use of customer relationship management (CRM) as the three main strategies affecting the agility of the supply chain in the industry Pharmacy are higher priorities, followed by the culture of variability, training programs and human resource empowerment programs, deployment and use of technology and flexible manufacturing systems, privatization in the supply chain, the use of flexible and agile organization structures, establishing appropriate performance evaluation, creating a strong relationship based on trust in the chain and outsourcing are secondary ranks.

\section{References}

Jafarnejad, Ahmed, Darwish, Maryam, "Evaluate agility in the supply chain (a case study)", Journal of Research Administration, year 9 , No. 2 (row 36), 2009

Azar, Adel; Tizro, Ali, Moqbel; Anvari Rostami, Ali Asqar., "agile supply chain model, modeling approach (interpretive -structural)", Studies in Management, Volume 14, Number 4, 2010

Zand Hesami, Hesam; Rajab Zadeh, Ali; Toloee, Abass, "The factors affecting supply chain agility (PSCM), and the design of agile supply chain management conceptual model ", Journal of Business Research, No. 51, 2009

Khodaverdi, Rohallah, Zohreh Boroujerdi, Ehsan, "Outsourcing strategy, benefits, problems and challenges" parks and incubators Journal, seventh year, No. 25, Winter 2010

Fathi, Mehdi, Golchinpour, Mona, Khosroshahi, Soror, "Agility solutions to manufacturing organizations", Tadbir Journal, No. 175, December 2006

Ghasemi, Amir Muhammad, Zivdar, Mehdi, Akaty, Hamid, "Flexible production system of agile manufacturing facilitators ", the first International Conference on Management and Innovation, 2010

Khodami, Soheila; Khodad Hosseini, Seyed Hamid, Moshabaki, Asaghar, Azar, Adel; " Customer agility model design with organizational dynamic capability approach: The role of consciousness competency entrepreneurial and nimble market", Journal of Modern Marketing Research, the second year, the first number, serial number (4) spring 2012

Menhaj, Mohammad Bagher, first published in 2007, the fuzzy calculation, Daneshnegar publication

Power D, Sohal A, Rahman S (2001). Critical success factors in agile supply chain management, Intrnational Journal of Physical Distribution \& Logistics management; 31(4).

Rachel Mason-Jones*, Denis R. Towill, "Total cycle time compression and the agile supply chain", Int. J. Production Economics 62 (1999) 61\}73, LSDG, MASTS Cardiw University, P.O. Box 907, Cardiw, CF1 3YB, UK Industrial Marketing Management, Vol 29., No. $1,2000$.

Alshawi, S., Saez-Pujol, I., \& Irani, Z. (2003). Data warehousing in decision support for pharmaceutical R\&D supply chain. International Journal of Information Management, 23, 259-268. 
Wu, C., \&Barnes, D. (2010). Formulating partner selection criteria for agile supply chains: A Dempster-Shafer belief acceptability optimization approach. Int. J. Production Economics, 125(2), 284-293.

Christopher M, Towill D.R (2002). An integrated model for the design of agile supply chains, International Journal of physical Distribution and logistics; 31(4).

Christopher M (2000). The Agile supply chain: Competing in volatile Markets, Industrial Marketing Management; 29.

Tolon W.J (2000). Virtual situation room: Connecting people across enterprises for supply chain agility, Computer Aided Design; 32.

Svensson G (2001). Perceived trust towards suppliers and customers in supply chains of the Swedish automotive industry, International Journal of physical Distribution and Logistics Management; 31(9).

Baker P (2008). The design and operation of distribution centre within agile supply chains, International Journal of Production Economics; 111.

Agarwal A, Shankar R, Tiwari M.K (2007). Modeling agility of supply chain, Industrial Marketing Management; 36.

Bal J, Wilding R, Goundry J (1999). Virtual teaming in the agile supply chain, International Journal of Logistics Management; 10 (2).

Stratton R, Warburton R.D.H (2003). The strategic integration of agile and lean supply, International Journal Production Economics; 85.

Holweg M (2005). The three dimensions of responsiveness, International Journal of Operations \& Production Management; 25 (7).

Swafford P.M, Ghosh S, Murthy N (2008). Achieving supply chain agility through IT integration and flexibility, International Journal of Production Economics; 116.

Giachetti R.E, Martinez L.D, Saenz O.A, Chin-Sheng C (2003). Analysis of the structural measures of flexibility and agility using a measurement theoretical framework, International Journal of Production Economics; 86.

Yusef Y.Y, Sarhadi M, Gunasekaran, A., (1999). Agile manufacturing: the drivers, concepts and attributes, International Journal of Production Economics; 62.

Christopher, Martin ;( 2004): Creating agile supply chain, Cranfield school of management.

Greaver, M.F. (1999) "Strategic Outsourcing -A Structured Approach to Outsourcing Decisions and Initiatives", AMA Publications, Inc, USA.

Raschke R. L.;"Process-based view of agility: The value contribution of IT and the effects on process outcomes"; International Journal ofAccounting Information Systems, 11(4), 2010.

Shepherd, Craig (2006), "Measuring supply chain performance: current research andfuture directions", International Journal of Productivity and PerformanceManagement, Vol. 55 No. 3/4, pp 25-31.

Lin, F. and H. Ying, (2007) Decision-making in fuzzy discrete event systems. Information Sciences, 177, 3749-3763.

Cheng, s. k. (2000), Development of a fuzzy multi-criteria decision support system for municipal solid waste management. Regina: a thesis in graduate studies and research university of Regina.

Petroni A. and A.Rizzi, (2002), Fuzzy logic based methodology to rank shop floor dispatching rules. International Journal of Production Economics, 76, 99-108.

Rao, R. V. and Davim, J. P. (2008), "Decision-Making Framework Models for Material Selection Using a Combined Multiple Attribute Decision-Making Method", J. of Adv Manufacturing Technology, 35, 751-760.

Shih, H. Sh.; Shyur, H. J. and Lee, E. S. (2007), "An Extension of TOPSIS for Group Decision Making", Mathematical and Computer Modelling, 45, 801-813.

Wang, Y. J. (2008), "Applying FMCDM to Evaluate Financial Performance of Domestic Airlines in Taiwan", Expert Systems with Applications, 34, 1837-1845. 